\title{
VAMOS FALAR E EDUCAR SOBRE GÊNERO
}

\author{
Carolina Chaves Ferro'
}

RIBEIRO, Marcos (org.). A conversa sobre gênero na escola: aspectos conceituais e político-pedagógicos. Rio de Janeiro: Wak editora, 2019.

Uma mulher é vítima de estupro a cada nove minutos. Uma pessoa trans ou gênero-diversas é assassinada a cada dois dias. A cada dia, três mulheres morrem vítimas de feminicídio. A maioria dos casos de violência sexual contra crianças e adolescentes ocorre em casa. Todos esses dados foram retirados do site Violência contra as mulheres em dados que reúne pesquisas realizadas no Brasil sobre violência de gênero. O nosso país é estruturalmente patriarcal e, para mudar uma estrutura desse tipo, como já dizia Gramsci (1982), é necessário mudar a cultura, desconstruir o aparelho hegemônico, neste caso o patriarcado, e o início dessa luta se dá pela educação. É nesse sentido que o livro organizado por Marcos Ribeiro pode ser considerado um diamante em meio a tempos tão obscuros.

Composto por 16 capítulos e "bate-papos pedagógicos", A conversa sobre gênero na escola traz diferentes aspectos da questão de gênero. Além disso, como afirma Butler (2003), não é possível pensar gênero sem questionar a categoria da sexualidade. Por isso, o livro também traz essas abordagens de maneira leve, agradável e didática. Isto significa que não é preciso ser um grande especialista para entender e começar a discutir gênero e sexualidade nas escolas, basta ter boa vontade e este livro em mãos.

Já na apresentação, Marcos Ribeiro descontrói os papéis de gênero culturalmente impostos em nossa sociedade e apresenta a importância de se abordar gênero e sexualidade em sala de aula. Além de uma visão de sociedade mais igualitária, busca-se, com a obra, cumprir com a nossa lei maior, a Constituição Federal e com os Parâmetros Curriculares Nacionais.

O primeiro capítulo, escrito por Eliane Rose Maio é introdutório dos conceitos centrais e de seus históricos, situando os leitores num debate sobre autoras e feminismo. Afinal, não há como deixar de lado esse movimento social que permitiu que o debate sobre gênero fosse discutido nas universidades pelo mundo. Também seria impossível estudar gênero sem recordar que as mulheres foram, durante tanto tempo, excluídas da História. Maio rememora o início da discussão da história das mulheres com nomes como Rachel Soihet (a qual tive a sorte de ser aluna), Joana Maria Pedro, Margareth Rago dentre tantas outras personagens pioneiras. Contudo, apesar dos estudos terem avançado, nem todas as faculdades dão a devida atenção a essas temáticas. Maio lembra que esses estudos devem ser discutidos na universidade, especialmente entre mulheres que ainda reproduzem o machismo em seu cotidiano. Por último, ela propõe uma reflexão sobre diferenças de gênero, tentando fazer com que os leitores questionem sua própria vida e verifiquem quantas vezes o masculino foi prioritário em nossas escolhas. O capítulo seguinte, escrito por Maria do Carmo de Andrade Silva, destaca a importância da interdisciplinaridade na discussão sobre gênero e sexualidade no que tange aos conceitos, para que cada área do conhecimento não desenvolva uma definição própria que prejudique as pesquisas em prol do fim do preconceito e da discriminação. A autora também aborda a questão física do sexo biológico que é bem mais complexa do que a maioria das pessoas pensa com seu pouco aprendizado de genética na escola básica. Ao refletir de forma multidisciplinar, passando por autores como Rogers e Freud, por exemplo, Silva destaca que a identidade de uma pessoa tem aspectos biopsicossociais, sendo, segundo suas palavras "algo muito maior que papel de gênero, que orientação sexual ou atividade sexual - fatores que a compõem, mas não a definem".

O terceiro capítulo trata da abordagem de gênero com crianças e adolescentes, produzido por Vânia Beliz. A autora aponta que a própria educação, seja em casa ou na escola acaba restringindo as crianças aos papéis de gênero preestabelecidos. Mas, mesmo que os pais não consigam trazer essa desconstrução dos papéis, cabe à

\footnotetext{
Historiadora, doutora em História social pela Universidade Federal Fluminense (UFF) com estágio sandwich na Universidade Nova de Lisboa. Mestre em História Social e bacharel e licenciada em História pela UFF. Professora Adjunta de Pedagogia, Jornalismo e Publicidade no Centro Universitário Carioca (UniCarioca). Editora da Revista do Arquivo Geral da Cidade do Rio de Janeiro (AGCRJ). Membro do grupo de pesquisa Scriptorium, da UFF e do Núcleo de Estudos Interdisciplinares em Comunicação (NEICOM), da UniCarioca. Atualmente pesquisa democracia e redes sociais com ênfase na questão de gênero e do feminino, com financiamento do Conselho Nacional de Desenvolvimento Científico e Tecnológico (CNPq) e trabalha na revisão editorial do Grupo Raiz Educação.
} 
escola, um espaço onde todos lidarão com as diferenças, saber se colocar como a parte que irá desconstruir o status quo e, para isso, os educadores e outros agentes escolares precisam igualmente se desconstruir. No quarto capítulo, Caroline Arcari trata da importância de empoderarmos as meninas para abolirmos o machismo em nossa sociedade. Iniciando com um histórico sobre preferências de meninos e meninas, demonstrando que não há razões genéticas para elas, a autora perpassa discussões como a violência imposta às meninas para seguirem determinados padrões do senso comum. Arcari também se utiliza de um documento do Fundo das Nações Unidas com cinco motivos para empoderarmos as meninas, como levar em conta a questão dos direitos humanos que aponta que todo ser humano tem o direito de ser responsável pelo seu futuro, suas escolhas, sua liberdade. Para finalizar o artigo, a autora salienta a importância da masculinidade positiva, pois os meninos também sofrem com o machismo - ainda que não na mesma medida - e a escola pode auxiliar nessa desconstrução dos papéis, mostrando que meninos podem ser sensíveis, praticar atividades de cuidado da casa e dos filhos tal como as meninas podem ser fortes, sustentar financeiramente suas famílias e serem donas de seu próprio destino.

O capítulo 5 é especial, pois foi escrito por um adolescente de 15 anos, Fabricio Pupo Antunes. O pesquisador prodígio traz um olhar do outro lado, o de aluno do ensino médio, tentando pensar a produção das identidades num ambienteescolar. Fabricio contaa história de Marcelo (nome fictício) seu colega que andava sempre entre as meninas - e havia uma dúvida sobre sua sexualidade e gênero por isso. Antunes nos demonstra, através de sua observação, que os próprios adolescentes são repletos de dúvidas e questionamentos sobre gênero e sexualidade e cabe à escola e aos educadores também perceberem os comportamentos de seus alunos e trabalharem as diferenças. Além da observação, Fabricio possui um blog chamado Transidentidades, local onde vários adolescentes de Mato Grosso do Sul responderam sobre questões de gênero e sexualidade nas escolas. $O$ autor percebeu que se a escola apoia as diferenças, esses alunos se sentem mais incluídos na sociedade que, normalmente os exclui, podendo se desenvolver de forma mais plena. Já o próximo capítulo, o sexto, de Tereza Cristina Pereira Carvalho Fagundes, fala sobre as políticas educacionais associadas à questão de gênero. Além de contextualizar o conceito, Fagundes aponta a Constituição Federal (1988), a Lei de Diretrizes e Bases (1996), os Parâmetros Curriculares Nacionais (1997) e o Plano Nacional de Educação (200I) somados às políticas educacionais como Programa Nacionais de Direitos Humanos II e III, a Agenda 2030 para o Desenvolvimento Sustentável, o Projeto Gênero e Diversidade na Escola e o Programa Brasil sem Homofobia como sendo as diretrizes para as quais devemos estar atentos na escola para a promoção da equidade de direitos. A autora trabalha especialmente os últimos documentos, demonstrando como o trabalho com a diversidade não é apenas algo necessário, como está previsto em lei e na política pública do Estado brasileiro e de organismos internacionais como a Organização das Nações Unidas. A autora destaca com maestria que vivemos períodos de retrocessos, mas que a luta deve continuar em prol da eliminação de qualquer discriminação por motivos de gênero, orientação sexual, religião e questões étnico-raciais.

O capítulo 7, de Fábio Meirelles também aborda os instrumentos normativos associados à prática educativa. Perpassando pelo mapa alarmante sobre violência de gênero em nossa sociedade, também em âmbito escolar, Meirelles apresenta documentos como diretrizes nacionais, programas e políticas públicas de educação, gênero e diversidade sexual para, depois, contextualizar as discussões em torno da aprovação desses instrumentos e apresentar casos de escolas e educadores que discutem equidade de gênero e diversidade sexual no ambiente escolar. O autor conclui que, mesmo que haja temas excluídos, por enquanto, dos instrumentos normativos - mas são associados à gênero e à sexualidade e são importantes para ampliar a discussão -, eles devem ser debatidos na escola, espaço visto como sendo o mais importante para a desconstrução. No capítulo seguinte, Rogério Junqueira perpassa um tema polêmico que é a invenção do termo "ideologia de gênero". Ele mostra que a criação partiu de grupos conservadores que possuem uma ideia tradicional de família que talvez nunca tenha existido de fato. Aponta o catolicismo como inventor do termo debatido no capítulo, perpassando por falas e documentos religiosos que pregam que a família só pode ser formada por heterossexuais. $O$ autor aponta, também, as principais estratégias discursivas dos movimentos antigênero, como a que ele considera central: "renaturalizar a ordem social, moral e sexual tradicional e apontar como antinaturais crenças, ideias ou atitudes que contrariem essa ordem". O interessante deste capítulo é que para criticarmos esse posicionamento que não vem da ciência, mas da religião, é preciso entender como esse tipo de pensamento foi construído e nos pautarmos nos direitos humanos e na equidade para garantir uma educação de qualidade e, ao mesmo tempo, democrática.

No capítulo 8, Mariana Braga lembra que o debate sobre sexualidade e gênero é um direito constitucional, sendo assim pétreo, ninguém pode nos proibir de abordar esse assunto, onde quer que seja. Ela destaca a ameaça que temos sofrido ao tratar desses assuntos nas escolas e, por isso mesmo, é muito importante que saibamos nossos direitos democráticos para continuar promovendo esses debates. Grande conhecedora da Constituição Federal e da Declaração Universal dos Direitos Humanos, Braga precisa nos lembrar que os direitos se estendem a todos, 
independentemente de raça, sexo, nacionalidade, etnia, idioma ou quaisquer outras condições, como a sexualidade e o gênero. $A$ autora também aponta outros documentos de direito internacional e documentos educacionais brasileiros para comprovar que os docentes possuem largo arcabouço jurídico que permite a liberdade de tratar temas como gênero e sexualidade em sala de aula. $O$ capítulo 9 é do organizador do livro, Marcos Ribeiro, e fala sobre a prática em sala de aula. Como abordar um tema que ainda é tabu para tantos grupos sociais. Marcos tem dupla formação (Psicólogo e Pedagogo) e ampla experiência nacional e internacional para falar com precisão cirúrgica que é necessário empenho da escola. Sendo assim, o Projeto Político Pedagógico, por exemplo, precisa conter elementos de discussão das questões de gênero e sexualidade. Ribeiro dá ideias para professores de diversas áreas, como português, ciências, história, geografia, artes, educação física, matemática, informática, mostrando que é possível sim trabalhar em qualquer momento e disciplina, ou de forma interdisciplinar. Para isso, é necessário que o professor esteja bem preparado e este livro contribui para isso.

No capítulo II, Christina Gonçalves e Virgínia Ribeiro trabalham a interface entre educação e saúde no que diz respeito ao gênero. As autoras lembram que não há como falar dessa temática sem tratar o corpo, afinal, é comum as pessoas sem conhecimento do assunto confundirem sexo com gênero, por exemplo. Além disso, a própria educação sexual é necessária e deve ser bem vista na escola. É através dela que evitamos que nossos adolescentes adoeçam com infecções sexualmente transmissíveis ou tenham uma gravidez indesejada, tendo em vista que eles estão no início de suas vidas. Gonçalves e Ribeiro também apontam dados sobre as Infecções Sexualmente Transmissíveis (IST) e sobre os problemas de saúde ocasionados pelo tabu da sexualidade e pelo machismo. É o caso, por exemplo, de homens que têm doenças por não higienizarem corretamente seus pênis. Um dos elementos mais interessantes do artigo é que, além de abordar a importância do trabalho conjunto de educadores e agentes de saúde, elas apontam estratégias para praticar esse trabalho com eficácia nas escolas. O capítulo 12, de Ana Canosa aborda a importância da parceria família-escola diante ao debate sobre gênero. Como já apontamos durante toda a análise desse livro, a escola tem papel primordial, mas de nada adianta se não há parceria com a família, o primeiro grupo de socialização do indivíduo. Canosa lembra que se a desconstrução dos papéis de gênero começar em casa, fica muito mais fácil trabalhar essas questões na escola. A imposição dos papeis de gênero desde o nascimento prejudica que essas crianças se enxerguem como iguais em condições, em inteligência e em direitos. Como aponta a autora, isto não quer dizer ignorar os corpos biológicos, mas permitir que as crianças se identifiquem naturalmente com seus grupos. A escola, neste sentido, deve ter o papel de se posicionar firmemente na luta pela equidade de gênero, ainda que algumas famílias tenham dificuldade em aceitar essa questão. $O$ mesmo ocorre em relação à sexualidade. Muitas vezes, crianças e adolescentes não são aceitos em seu seio familiar e encontram na escola uma proteção. Se a escola promover a diferença ao invés da equidade, o sofrimento desses indivíduos será ainda maior. Por último, a autora lembra que o próprio conceito de família é histórico e que muitas famílias compostas por responsáveis homossexuais já existem. As crianças dessas famílias devem ser acolhidas.

O capítulo I3, escrito por Bruno Ganem demonstra como o teatro pode ajudar na desconstrução de estereótipos e trabalhar a diversidade. $O$ autor fala da experiência do exercício teatral "Na minha pele", que traz à cena questões como gênero, sexualidade, orientação sexual e raça. Ganem conta toda a experiência com os alunos desde a inscrição até a construção dos atos, as atividades com improvisação e jogos, finalizando com uma linda poesia de um dos alunos sobre a homofobia. $\mathrm{O}$ autor nos mostra através de um excelente arcabouço teórico do plano das artes - passando pelas leis e por Boal, por exemplo - que o teatro é palco para as discussões do cotidiano e para a interação social da diversidade, sendo um excelente instrumento de aprendizagem e de libertação dos padrões opressores. O capítulo 14, de Marisa Gaudio, fala sobre violência de gênero, tema que iniciou esta resenha. Para pensarmos nesse assunto, antes de tudo é preciso compreender o que ela significa. Além de explicar a própria expressão, Gaudio apresenta números, os tipos de violência - apontando toda a legislação que a combate -, finalizando com a violência entre os alunos, elemento que a comunidade escolar irá conviver e que devemos saber como agir. Para enfrentar o problema, temos a Lei Maria da Penha, por exemplo, uma luta do movimento feminista para diminuir as agressões promovidas cotidianamente, principalmente, pelos homens em relação às mulheres. Neste sentido, a autora salienta que o educador deve ficar atento aos sinais de violência que seus alunos podem sofrer não só na escola, como em casa, seja por questões de gênero ou sexualidade.

O capítulo 15, de Rosiane Rodrigues de Almeida, aponta a questão de gênero associada à raça e ao racismo, elementos que podem potencializar a violência com pessoas que estão distantes da sociedade heteronormativa. Almeida aponta dados da Anistia Internacional para mostrar essa potencialização, afinal, numa sociedade extremamente racista como a que vivemos, a população negra está muito mais propícia a sofrer violência de todos os tipos. Para compreendemos melhor o que está sendo dito, a autora reforça o conceito de racismo que pressupõe uma relação de poder, onde os brancos dominam a maioria dos elementos de nossa sociedade. Quando há a associação 
74 Revista Brasileira de

Sexualidade Humana

DOI: https://doi.org/10.35919/rbsh.v30i2.295

entre racismo e homofobia, a questão é muito perigosa, pois os índices de violência são ainda maiores. Por sofrerem preconceitos dos mais variados e a escola também sendo uma reprodutora do racismo estrutural, esses indivíduos possuem altas taxas de evasão escolar. Devido a isto, a autora lembra que a escola, que devia ser um local de aprendizados e desconstruções, não tem sabido lidar com essas questões, sendo de suma importância olharmos para a questão do racismo em paralelo com a homofobia ou transfobia. O último capítulo do livro é de Marcelo Turra e fala sobre $o$ acesso a direitos civis e sociais das pessoas trans, abordando a questão dos registros escolares. Turra mostra que, ainda que a pessoa não tenha mudado seu nome no documento de identidade oficial, ela tem todo direito de usar seu nome social como modo de evitar constrangimento e de ter sua identidade de gênero preservada e respeitada. Para isso, o autor trabalha ambos os conceitos (nome civil e nome social), a decisão do Supremo Tribunal Federal, mostrando a lei em sua totalidade, a portaria do Ministério da Educação abordando o direito das pessoas trans de usar seu nome social - que pode ser utilizado inclusive em provas como ENEM -, celebrando as conquistas no âmbito cível dessas populações que vêm lutando por seus direitos há tantos anos. Esse artigo deve ser consultado por educadores para auxiliar seus alunos na garantia do respeito aos seus direitos.

Entre um capítulo e outro temos sugestões de atividades práticas com os alunos na instituição escolar. Elas servem, não só para os professores se prepararem melhor para lidar com questões de gênero e sexualidade, como podem contribuir para toda a comunidade escolar debater esses assuntos e tornar a convivência na escola mais pacífica e respeitosa com todas as orientações e papéis que nós, indivíduos, almejamos ter.

Voltando à apresentação, como afirma Ribeiro, o livro foi feito para os professores, mas também para outros agentes da educação. Diríamos que, na verdade, ele foi feito para todos aqueles que desejam sair do senso comum e compreender melhor a diversidade humana. Talvez algumas temáticas ou abordagens tenham ficado de fora, mas isso não empobrece em nada o livro. Pelo contrário, nos dá expectativas por um novo volume. Esperamos que o organizador já esteja pensando nele, pelo bem da diversidade e da democracia.

\section{Referências}

BUTLER, Judith. Problemas de gênero: feminismo e subversão da identidade. Tradução: Renato Aguiar. Rio de Janeiro: Civilização Brasileira, 2003.

GRAMSCl, Antonio. Os intelectuais e a organização da cultura. Tradução: Carlos Nelson Coutinho.

Rio de Janeiro: Civilização Brasileira, 1982. 